\title{
The association of breastfeeding self- efficacy with breastfeeding duration and exclusivity: longitudinal assessment of the predictive validity of the Greek version of the BSES-SF tool
}

Mary Economou ${ }^{1 *}$, Ourania Kolokotroni ${ }^{2,3}$, Irene Paphiti-Demetriou ${ }^{3}$, Christiana Kouta $^{1}$, Ekaterini Lambrinou', Eleni Hadjigeorgiou', Vasiliki Hadjiona ${ }^{1}$ and Nicos Middleton ${ }^{1}$

\begin{abstract}
Introduction: While breastfeeding self-efficacy (BSES) is an important modifiable determinant of breastfeeding, a structured assessment is not standard practice in Cyprus. We assessed the Greek version of the Breastfeeding SelfEfficacy Scale (BSES-SF), including its predictive validity in terms of Breastfeeding (BF) and Exclusive Breastfeeding (EBF) up to the sixth month.

Methods: A methodological study with longitudinal design among 586 mother-infant dyads, as part of the "BrEaST Start in Life" project. BSES was assessed 24-48 h after birth and at the first month. Breastfeeding status was assessed at the clinic, the 1st, 4th and 6th month. The association between BSES and breastfeeding was estimated in logistic regression models and its diagnostic ability in ROC analysis.

Results: With Mean $=3.55$ (SD = 0.85), BSES was moderate, and lower among Cypriot women, primiparas and those who delivered by Cesarean Section (C/S). There was good internal consistency across the 14 items (Cronbach's $a=$ 0.94) while factor analysis revealed a two-factor structure. BSES scores were higher among mothers who initiated exclusive breastfeeding ( $M=3.92, S D=0.80)$ compared to breastfeeding not exclusively $(M=3.29, S D=0.84)$ and not breastfeeding $(M=3.04, S D=1.09 ; p$-value $<0.001)$. There was a stepwise association with exclusivity $(40.5 \%$ in the highest vs $7.9 \%$ lowest quartile of self-efficacy). The association between in-hospital BSES and long-term EBF persisted in multivariable models. Women in the upper quartile of BSES at $48 \mathrm{~h}$ were more likely to breastfeed exclusively by adjOR $=5.3(95 \% \mathrm{Cl} 1.7-17.1)$ at the 1 st and adjOR $=13.7(95 \% \mathrm{Cl} 2.7-68.6)$ at the 4 th month. Similar associations were observed between self-efficacy at the 1st month and BF at subsequent time-points. High first month BSES (> 3.96 as per ROC) had 58.9\% positive and 79.6\% negative predictive value for breastfeeding at 6 months which reflects higher sensitivity but lower specificity.
\end{abstract}

\footnotetext{
* Correspondence: economoum80@hotmail.com

'Department of Nursing, School of Health Sciences, Cyprus University of Technology, Limassol, Cyprus

Full list of author information is available at the end of the article
}

(c) The Author(s). 2021 Open Access This article is licensed under a Creative Commons Attribution 4.0 International License, which permits use, sharing, adaptation, distribution and reproduction in any medium or format, as long as you give appropriate credit to the original author(s) and the source, provide a link to the Creative Commons licence, and indicate if changes were made. The images or other third party material in this article are included in the article's Creative Commons licence, unless indicated otherwise in a credit line to the material. If material is not included in the article's Creative Commons licence and your intended use is not permitted by statutory regulation or exceeds the permitted use, you will need to obtain permission directly from the copyright holder. To view a copy of this licence, visit http://creativecommons.org/licenses/by/4.0/ The Creative Commons Public Domain Dedication waiver (http://creativecommons.org/publicdomain/zero/1.0/) applies to the data made available in this article, unless otherwise stated in a credit line to the data. 
Conclusions: The Greek version of BSES-SF showed good metric properties (construct, know-group, concurrent and predictive validity). In the absence of community support structures or programmes in Cyprus, prevalence of breastfeeding remains low. This suggests a need for policy, educational and community support interventions, including the systematic use of BSES scale as a screening tool to identify those at higher risk for premature BF discontinuation.

Keywords: Breastfeeding, Exclusivity, Breastfeeding self-efficacy, Reliability, Validity

\section{Introduction}

Breast milk is the optimal source of infant nourishment and addresses physiological and psychological requirements of the newborn during the first months of life. Numerous studies confirm the short- and long-term beneficial effects of breastfeeding for both infant and mother $[1,2]$. To achieve optimization of all health benefits, the World Health Organization suggests exclusive breastfeeding (EBF) for the first 6 months and continued breastfeeding (BF) until 2 years of age or beyond [3]. Currently, prevalence of exclusive breastfeeding for infants aged 0-6 months does not exceed 38\% [4]. This falls short of the World Health Assembly Global target for Nutrition by 2025, which called for an increase in the global rate of exclusive breastfeeding in the first 6 months to at least $50 \%$ [5]. A recent publication by Rito at el (2019) suggested that exclusive breastfeeding rates for at least 6 months range from $73.3 \%$ in Tajikistan to $10.5 \%$ in Italy [6].

Even though the majority of women in Cyprus initiate breastfeeding while at the maternity clinic, in terms of exclusive breastfeeding, Cyprus ranks in the lowest positions in Europe [7]. The BrEaST start in life study documented the maternity clinic practices in relation to the implementation of the 10 steps for successful breastfeeding [8] and provided first-time estimates of the prevalence of breastfeeding and exclusive breastfeeding beyond $48 \mathrm{~h}$ [9]. The prevalence of exclusive breastfeeding was as low as $18 \%$, even at $48 \mathrm{~h}$, while by the sixth month, one in three women continues breastfeeding but only 1 in 20 exclusively [9], an estimate even lower than previously reported figures. There is an extensive literature on several determinants that contribute to the low breastfeeding rates, including demographic, lifestyle, psychosocial and biomedical factors. In order to tackle the low breastfeeding rates, emphasis should be given to modifiable determinants. Maternal Breastfeeding Selfefficacy has been identified as one of the strongest modifiable predictors of breastfeeding initiation, duration and exclusivity [10, 11]. On the basis of Bandura' s SelfEfficacy Theory [12], Dennis developed a theoretical framework of the effect of maternal breastfeeding selfefficacy, defined as the mother's perceived ability to breastfeed her infant, on breastfeeding outcomes [13]. Self-efficacy determines the performance of a specific behavior "as it reflects of the individual perceptions about their perceived ability, not their actual ability" [13]. As a cognitive process, a strong sense of selfefficacy results in a positive perception and success promoting thought patterns with regards to the mother's ability to breastfeed. In contrast, low self-efficacy is more likely to be associated with negative experiences as well as thought patterns and emotional reactions. For example, when a mother expects to fail to breastfeed, she perceives it as discouraging and overwhelming $[14,15]$. In turn, this is more likely to result in early breastfeeding discontinuation. The 33-item Breastfeeding Self-Efficacy Scale was developed based on this theoretical model with the aim to identify mothers at risk to discontinue breastfeeding [10]. Due to item redundancy, a shorter 14-item form of the scale with similar psychometric properties was proposed [16]. The BSES-Short Form has been translated and validated in many languages, including Polish [17], Croatian [18], Hong Kong Chinese [19], Turkish [20], Swedish [21], Portuguese [22] and Spanish [23]. It has been extensively used in studies among the general population of mothers or specific population groups; adolescents [24], primiparas [25-27], ethnic minorities [28-30], low income [31] and many more. Only recently, a 9-item exclusive breastfeeding specific selfefficacy scale was developed on the basis of Dennis BFSE-SF scale to assess EBF where breastfeeding is common, with very good psychometric properties [32]. Research evidence suggests a positive predictive association of breastfeeding self-efficacy and breastfeeding initiation, duration and exclusivity [17, 18, 20, 22-24, 31]. Assessment of maternal breastfeeding self-efficacy prenatally or/and postnatally can identify women at high risk of breastfeeding discontinuation and thus in need of breastfeeding support.

The BSES scale, either in its original or short form, is most widely used scale in the literature. Even though the BSES was available in Greek (personal contact with the developer), no study assessing the breastfeeding selfefficacy of Greek or Greek-Cypriot mothers had been identified in the published or grey literature at the time of designing the study protocol. The purpose of this study was to assess some of the metric properties of the Greek version of the Breastfeeding Self-Efficacy Scale short form (BSES-SF) with a focus on its predictive 
validity among a sample of women giving birth in Cyprus. Specifically, the objectives of the study were to assess the dimensionality of the scale (factor validity), known-group validity (based on the assumption that self-efficacy is expected to higher in multiparas vs primiparas), concurrent validity (against initiation of breastfeeding at $48 \mathrm{~h}$ and exclusivity status) and finally, its predictive validity (against continued breastfeeding up to the sixth month) which even though not always considered in similar studies, it would support its usefulness as a potential screening tool.

\section{Methods}

\section{Study design}

This methodological study with longitudinal design was part of the wider research program "BrEaST start in life" aimed at strengthening the evidence-base around breastfeeding in Cyprus. The programme explored various determinants of breastfeeding, including the degree of implementation of the Baby-Friendly Hospital Initiative's "10 steps for successful breastfeeding", which form the basis of the National Strategy and Policy of the Cyprus National Breastfeeding Committee. The parent study was a nationwide cross-sectional (at phase I) and longitudinal (phase II) descriptive study. The study design was described in detail previously [9]. In brief, a nationwide sample of mothers was recruited cross-sectionally in the first phase from maternity clinics with the main aim to assess the extent and degree to which the WHO 10 steps are implemented. At phase II, mothers recruited at phase I were followed up prospectively with a telephone interview at three time points: first, fourth and sixth month. This allowed first-time estimates of the prevalence of any and exclusive breastfeeding in Cyprus since the only available official reported statistics simply refer to the first $48 \mathrm{~h}$. The study participants also provided information about a range of potential determinants of breastfeeding at each contact, including breastfeeding self-efficacy, which is the focus of this article.

\section{Study setting}

All maternity clinics in Cyprus were formally invited to participate and maternity wards in state hospitals (5 in total) and 24 of 30 private clinics agreed to participate. A convenience consecutive sample of mother-infant dyads was recruited during stay at the maternity clinics based on pre-defined criteria (see section below). The recruitment period was constant across all sites (6-8 weeks) in order to approximate the correct distribution of births across settings, as there is no official clinic-level record of the number of births in the private sector, which nevertheless accounts for over $70 \%$ of births. Trained field workers approached the women between
24 and $48 \mathrm{~h}$ after birth and asked them to complete a battery of self-administered questionnaires while waiting outside. Mothers who consented to participate at the next phase of the study, were followed up with a telephone interview. Breastfeeding self-efficacy was assessed in-hospital and at the 1st month telephone follow-up. Infant feeding practices, including breastfeeding and exclusive breastfeeding status, were assessed at all contacts with participants i.e. $48 \mathrm{~h}, 1 \mathrm{st}$, 4th and 6th month.

\section{Eligibility criteria}

Mothers were eligible to participate if they gave birth to a live infant in the participating clinics during recruitment, irrespective of whether they had a single or multiple pregnancy, they were at least 18 years of age, could read or speak Greek or English, had no health problems precluding them from breastfeeding, as recorded in the medical file and/or communicated to the team by the clinic staff (e.g. bilateral mastectomy, postpartum maternal complications) and were not separated from their infants after birth for medical reason, which would not allow breastfeeding initiation within $1 \mathrm{~h}$, e.g. transferred to NICU at the same hospital or at a different location (low birth weight $<2500 \mathrm{~g}$, gestational period $<37$ weeks). The socio-demographic and clinical (e.g. C/S rates) profile of participants was compared to official national figures to assess representativeness of sample. Sociodemographic characteristics of non-participants or participants lost-to-follow up were also used to assess the extent of possible selection bias.

\section{Measurement tools}

At baseline, mothers were asked to complete the Perceived Breastfeeding Self-efficacy scale - short-form (BSES-SF), developed by Dennis \& Faux [10]. This was included in a questionnaire pack with consisted of three sections: (a) the WHO/ UNICEF questionnaire - Section 4 [33] on the self-reported experience of the "10 Steps for Successful Breastfeeding", (b) the breastfeeding selfefficacy scale and (c) socio-demographic information. Participating mothers were asked to provide information on parity, breastfeeding history, intention to breastfeed, lifestyle factors (e.g. smoking, alcohol) and other. At the first month telephone follow-up, breastfeeding mothers completed the BSES-SF.

Information on infant feeding practices was collected at each subsequent contact, such as the type as well as time of introduction and frequency of supplemental feeding including formula, other liquids, solids, medication, vitamin, mineral drops or Oral Rehydration Solution (ORS). Self-reported current status, 24-h recall as well as a retrospective event calendar method were used to estimate the prevalence of breastfeeding (defined as breast milk in addition to any other liquid or food, 
including formula) and exclusive breastfeeding (defined as no other liquids or solids other than breast milk, given from any source, with the exception of medication, vitamin or mineral drops, Oral Rehydration Solution). The definitions, questions and process for determining breastfeeding status was previously reported in detail [9]. Note that $24 \mathrm{~h}$ recall of feeding practices were recorded using a modified version of the Centers for Disease Control and Prevention IFP questionnaire used in the Infant Feeding Practices Study II (IFPS II) in order to take into consideration predominant local practices.

\section{Breastfeeding self-efficacy scale short form (BSES-SF)}

In its short-form, the BSES-SF contains 14 items with a five-point Likert scale response-set. All statement are phrased positively, and begin with the phrase 'I can always...'. The response scale ranges from $1=$ not at all confident and $5=$ very confident. The theoretical range of the scale is 14-70, with higher scores indicative of higher levels of breastfeeding self-efficacy. Commonly, the total score is calculated by aggregating the responses on all 14 statements. In this study, the average (rather than the overall) score was used i.e. dividing the total score by the number of items. Other than allowing the inclusion of a small number of questionnaires $(N=27)$ for which an answer was not provided on all 14 items, this allows to express the score on a scale of 1-5. There are no set cut-off values for the scale. However, it has been suggested that a 5-10 unit difference (approximately $0.5-1.0 \mathrm{SD}$ ) is clinically significant in terms of predicting breastfeeding success in the long-run. A 10unit difference in the aggregate score would correspond to 0.7 on a $1-5$ scale.

\section{Translation of the tool}

The tool was used with permission by the developer who provided an existing Greek translation of the scale, even though at the time of designing the study protocol, no study that have used the Greek version of BSES- or BSES-SF was identified in the literature.. A number of grammatical changes were deemed necessary, after a double forward-backward translation process, in order to improve readability. The main change was in terms of the correct use of the tense for the key verbs to refer to a continuing process (i.e. every time) as also intended by the use of the term "always" in every item and not as an isolated event which often was unintentionally the effect in the use of the wrong tense for the verb in the provided Greek version. A number of other syntactical changes were also deemed necessary to improve its readability, for example "I can always preserve my willingness to breastfeed" was more accurately and succinctly translated as "Млор $v \alpha \theta \eta \lambda \dot{\alpha} \zeta \omega$ " rather than "Млор $\sigma u v \varepsilon \chi i \zeta \omega$ v $\alpha$ $\theta \eta \lambda \alpha \dot{\sigma} \sigma \omega$ " in the original (which backwards translates as "I can always want to continue to breastfeed", which is not just more awkward to read but does not convey the same meaning. Any necessary changes were identified as a result of the translation process, debated and agreed by consensus among the research team. Alternative versions were discussed during the pilot testing of the tool for readability among 11 mothers who gave birth in Nicosia maternity clinics, before the launch of the nationwide study, after which no further changes were introduced. A study published subsequently (Iliadou et al. 2020) used the tool in a Greek speaking population in Athens. However, the authors of that study state that they used the translated version as provided by the developer without describing whether any changes were introduced. The Greek translation of the tool used in this study is included as an Additional file.

\section{Ethical considerations}

All necessary approvals were obtained from all involved bodies: Cyprus National Bioethics Committee, Research Promotion Committee of the Ministry of Health, which also grants access permission to state hospitals, and equivalently from the administration of all participating clinics. Furthermore, notification was sent to the Commissioner of Personal Data Protection. Separate written consent was obtained for participating at each phase of the study in order to ensure higher participation at baseline. Mothers were informed that participation was volunteer and they could withdraw their participation at any time point of the study. Confidentiality and anonymity were assured.

\section{Sample size calculations}

Sample size calculation and, consequently the period of recruitment, was based on precision analysis with finite population correction (birth cohort around 10,000 annually) to estimate the prevalence of breastfeeding with $95 \%$ confidence interval not wider that $\pm 5 \%$, since this was the main aim of the parent study. This was estimated at a minimum required sample size of 370 but it was inflated to secure a sizeable sample at baseline to allow for potential drop-outs in the follow-up phases. The sample size, as estimated above, was also assessed using power analysis in terms of detecting an association between breastfeeding outcomes and a range of determinants of breastfeeding based on the range of estimates observed in previous studies, including breastfeeding self-efficacy. Even though estimates in the literature for the association between breastfeeding self-efficacy and breastfeeding outcomes are not directly comparable, due to different study designs, analytical approaches and length of follow-up, studies commonly report estimates in the magnitude of 2.00 in the odds ratio scale for any 
breastfeeding, or higher in the case of exclusive breastfeeding, per 5-10 units increase in the aggregate BSES scores. It was estimated a priori that a sample size of 370 provided $90 \%$ power to detect an association in the magnitude of 1.7 in the odds ratio scale at the 5\% statistical significance level, which was within the range of expected association. A post-hoc power analysis was also performed to estimate the retrospective power of the actual sample size based on observed effect sizes, which were actually larger than originally anticipated. For instance, even with the slightly smallest sample at the 6th month of follow-up, it was estimated that the study had 90\% power to detect as little as 0.35 SD difference between two comparison groups of interest, which corresponds to about 4-point difference in the scale. In fact, 5.5-8.5 mean differences were recorded in breastfeeding self-efficacy scores between mothers who did and did not breastfeeding throughout the follow-up period, with the difference becoming larger as time progressed.

\section{Statistical analysis}

Maternal Breastfeeding Self-Efficacy was expressed as a continuous variable (i.e. average score) as well as an ordinal variable (i.e. quartiles of participants based on the score distribution). The choice of using a statistical criterion was preferable due to the lack of generally accepted or uniform cut-off points reported across studies and populations. Thus, the predictive validity of the scale was explored in terms of its association with breastfeeding status in logistic regression models across quartiles of participants with increasing BSES scores. The identification of potential determinants of breastfeeding self-efficacy, including assessing the known-group validity of the scale, were explored in terms of observed differences in mean BSES between subgroups of participants based on their sociodemographic and other characteristics in one-way analysis of variance (ANOVA) and independent t-test as appropriate. Visual assessment and statistical tests were used to assess the symmetry and normality of the distribution of the Breastfeeding Self-efficacy scores at $48 \mathrm{~h}$ and 1st month. Bonferroni post hoc comparisons were performed were necessary. Construct validity was evaluated through exploratory factor analysis with a principal components extraction with a varimax rotation to identify the dimensionality of the scale. Reliability was assessed using the Cronbach's alpha coefficient for internal consistency. Concurrent and predictive validity of BSES was explored with the investigation of the association of breastfeeding self-efficacy as measured at baseline and at first month with infant feeding practices postpartum. Odds ratios (and 95\% CI) of $\mathrm{BF} / \mathrm{EBF}$ at each time point across quartiles of increasing BSES were estimated in logistic regression models before and after adjusting for important covariates of BSES, as identified in multivariable stepwise linear regression models. The diagnostic ability of the scale was also assessed by calculating the receiver operating characteristics (ROC) curve and examining the area under the curve. The point on the ROC curve with the highest combined Sensitivity and Specificity as indicated by the area under the curve (AUC) was proposed as the potential cutoff point of the scale. G power was used for sample size calculations and SPSS for Windows Version 21(SPSS Inc., Chicago, IL, USA) was used for the analyses.

\section{Results}

\section{Participant characteristics}

The baseline sample consisted of 586 mother-infant dyads (response rate $73.5 \%$ among the 797 consecutive sample eligible to participate), approximating the expected national distribution of births across districts and 70:30 split between private and public sector (not presented in detail). Of those, 372 (response rate: 63.5\%), 383 and 340 mothers respectively participated at the first, fourth and sixth month follow-up. The total number of mothers who completed the BSES-SF scale at $48 \mathrm{~h}$ and 1st first month was 504 and 284 respectively, since with a few exceptions, those who did not initiate breastfeeding or were not breastfeeding at the time of assessment did not respond to the scale. As shown in Table 1, the majority of women were aged $25-29$ years $(46.3 \%)$ and $30-34(21.0 \%)$. Only $6.3 \%$ of participating mothers were older than 35 years of age. The percentage in the sample who were of Cypriot origin was $77.2 \%$, which is consistent with official statistics. In terms of educational attainment, $57.3 \%$ had either undergraduate or postgraduate tertiary education. For $48.9 \%$ of mothers, this was their first child. Among the rest, 44.7\% reported previous breastfeeding experience. As reported previously [9], the prevalence of breastfeeding at $48 \mathrm{~h}$ was 84.3\% (95\% CI 81.4-87.3\%). Even though the true prevalence of exclusive breastfeeding was only $18.8 \%$ (95\% CI 15.6-21.9\%), 81.9\% of mothers reported their intention to breastfeed exclusively and $76.6 \%$ to do so for at least 6 months. It is of note that as many as $55.8 \%$ delivered by $\mathrm{C} / \mathrm{S}$, which is consistent with officially published data.

\section{Internal consistency of BSES-SF}

The internal consistency of the scale was estimated by Cronbach's $\alpha$ coefficient at 0.94 , which is identical to the one reported in the original study [16]. There was no increase by more than 0.1 in the alpha coefficient in response to the deletion of any items. The inter-item correlations ranged between 0.26 to 0.82 , with a mean of 0.55 .

\section{Breastfeeding self-efficacy by socio-demographic characteristics}

The mean breastfeeding self-efficacy score was 3.55 $(\mathrm{SD}=0.85$, median $=3.57, \mathrm{IQR}=2.71-4.04$, range $1-5)$ 
Table 1 Participants' characteristics and perceived breastfeeding self-efficacy by socio-demographic and other characteristics

\begin{tabular}{|c|c|c|c|c|c|c|}
\hline & $N(\%)^{\mathrm{a}}$ & $\begin{array}{l}\text { BSES-SF } \\
\text { Mean (SD) at } 48 \mathrm{~h}\end{array}$ & $p \neq$ & $N(\%)^{\mathrm{a}}$ & $\begin{array}{l}\text { BSES-SF } \\
\text { Mean (SD) } \\
\text { at 1st month }\end{array}$ & $p \neq$ \\
\hline \multicolumn{7}{|l|}{ Age } \\
\hline $18-24$ & $126(25.3)$ & $3.43(0.85)$ & 0.45 & $62(23.1)$ & $4.04(0.68)$ & 0.94 \\
\hline $25-29$ & $231(46.4)$ & $3.41(0.90)$ & & $129(47.9)$ & $4.00(0.80)$ & \\
\hline $30-34$ & $108(21.7)$ & $3.31(0.96)$ & & $59(21.9)$ & $3.96(0.91)$ & \\
\hline$\geq 35$ & $33(6.6)$ & $3.59(0.90)$ & & $19(7.1)$ & $4.06(0.66)$ & \\
\hline \multicolumn{7}{|l|}{ Education } \\
\hline At most secondary & $208(42.6)$ & $3.41(0.90)$ & 0.03 & $116(44.3)$ & $4.03(0.77)$ & 0.75 \\
\hline Undergraduate & $162(33.2)$ & $3.51(0.91)$ & & $89(33.9)$ & $3.99(0.76)$ & \\
\hline Postgraduate & $118(24.1)$ & $3.22(0.85)$ & & $57(21.8)$ & $3.94(0.87)$ & \\
\hline \multicolumn{7}{|l|}{ Marital Status } \\
\hline Married/Cohabiting & $484(97.4)$ & $3.39(0.90)$ & 0.34 & $259(97.0)$ & $4.00(0.79)$ & 0.69 \\
\hline Other & $13(2.6)$ & $3.63(0.86)$ & & $8(3.0)$ & $4.10(0.69)$ & \\
\hline \multicolumn{7}{|l|}{ Employment Status } \\
\hline Full Time & $324(65.6)$ & $3.35(0.87)$ & 0.16 & $170(63.9)$ & $3.94(0.82)$ & 0.18 \\
\hline Part Time & $55(11.1)$ & $3.54(0.94)$ & & $33(12.4)$ & $4.04(0.68)$ & \\
\hline Unemployed & $115(23.3)$ & $3.49(0.92)$ & & $63(23.7)$ & $4.16(0.75)$ & \\
\hline \multicolumn{7}{|l|}{ Monthly Family Net Income } \\
\hline$<=€ 1500$ & $202(45.2)$ & $3.44(0.90)$ & 0.46 & $119(48.8)$ & $4.05(0.72)$ & 0.15 \\
\hline$€ 1501-€ 3000$ & $178(39.8)$ & $3.33(0.86)$ & & $86(35.2)$ & $3.88(0.86)$ & \\
\hline$>=€ 3001$ & $67(15.0)$ & $3.43(0.94)$ & & $39(16.0)$ & $4.09(0.82)$ & \\
\hline \multicolumn{7}{|l|}{ Country of Origin } \\
\hline Cypriot & $380(77.2)$ & $3.29(0.86)$ & $<0.001$ & $194(73.5)$ & $3.95(0.78)$ & 0.03 \\
\hline Not Cypriot & $112(22.8)$ & $3.83(0.88)$ & & $70(26.5)$ & $4.19(0.77)$ & \\
\hline \multicolumn{7}{|l|}{ Type of Birth } \\
\hline Vaginal & $223(44.2)$ & $3.57(0.87)$ & $<0.001$ & $135(49.1)$ & $4.17(0.73)$ & 0.002 \\
\hline C/S w/t Gen Anesthesia & $213(42.3)$ & $3.23(0.89)$ & & $93(33.8)$ & $3.93(0.81)$ & \\
\hline C/S w Gen Anesthesia & $68(13.5)$ & $3.37(0.93)$ & & $47(17.1)$ & $3.72(0.76)$ & \\
\hline \multicolumn{7}{|l|}{ Parity } \\
\hline First child & 246 (48.9) & $3.17(0.81)$ & $<0.001$ & $140(49.3)$ & $3.81(0.79)$ & $<0.001$ \\
\hline Multiparous w/t previous BF experience & $32(6.4)$ & $2.78(1.01)$ & & $7(2.5)$ & $3.70(1.18)$ & \\
\hline Multiparous w/ previous BF experience & $225(44.7)$ & $3.74(0.84)$ & & $137(48.2)$ & $4.23(0.67)$ & \\
\hline \multicolumn{7}{|l|}{ Intention to breastfeed exclusively } \\
\hline Yes & 405 (81.9) & $3.54(0.83)$ & $<0.001$ & $237(88.4)$ & $4.05(0.76)$ & 0.002 \\
\hline No & $92(18.5)$ & $2.80(0.94)$ & & $31(11.5)$ & $3.60(0.84)$ & \\
\hline \multicolumn{7}{|c|}{ Intention to breastfeed exclusively for 6 months } \\
\hline Yes & 377 (76.6) & $3.57(0.82)$ & $<0.001$ & 225 (84.9) & $4.08(0.75)$ & $<0.001$ \\
\hline No & $115(23.4)$ & $2.85(0.93)$ & & $40(15.1)$ & $3.53(0.85)$ & \\
\hline
\end{tabular}

$\neq p$-values as estimated using independent sample t-test or one-way ANOVA, as appropriate

${ }^{a}$ Total number of breastfeeding mothers who completed the BSES-SF scale at $48 \mathrm{~h}$ and 1 st first month: $N=504$ and $N=284$ respectively. Participants with missing socio-demographic information were excluded from the statistical analysis. The percentage of missing values was generally low and ranged between 0 and $7 \%$

( $N=488-504$ and 262-284 respectively), with the exception of family income $(N=447$ and 244 respectively)

within the first $48 \mathrm{~h}$ and $4.01(\mathrm{SD}=0.79$, median $=4.14$, $\mathrm{IQR}=3.57-4.64$, range $=1-5)$ at the first month assessment. Table 1 shows mean levels (SD) of BSES scores according to sociodemographic characteristics. A statistically significant difference in mean BSES scores was observed by mode of delivery. Mothers who had vaginal 
delivery were more likely to report higher levels of BSES at $48 \mathrm{~h}(3.57, \mathrm{SD}=0.87)$ compared to those who gave birth by $\mathrm{C} / \mathrm{S}$ with general anesthesia $(3.37, \mathrm{SD}=0.93)$ and $\mathrm{C} / \mathrm{S}$ with regional (not general) anesthesia (3.23, $\mathrm{SD}=\mathrm{SD}: 0.89 ; p$-value $<0.001)$. Even though BSES scores were generally higher for all by the first month, a significant difference across different types of delivery was still apparent, corresponding to a moderate effect size in the magnitude of 0.5 SD. Mothers who intended to EBF for 6 months reported significantly higher levels of BSES from the first $48 \mathrm{~h}(\mathrm{M}=3.37, \mathrm{SD}=0.82$ vs $\mathrm{M}=2.85$, $\mathrm{SD}=0.93 ; p$-value $<0.001)$. With regards to nationality, Cypriot mothers $(\mathrm{M}=3.29, \mathrm{SD}=0.86)$ were more likely to report lower levels of BSES than non-Cypriot mothers $(\mathrm{M}=3.83, \mathrm{SD}=0.88 ; \mathrm{p}-$ value $<0.001)$. This difference appeared smaller by the first month, but remained statistically significant $(p$-value $=0.026$ ).

Surprisingly, mothers with postgraduate education had the lowest BSES scores $(\mathrm{M}=3.22, \mathrm{SD}=0.85)$ compared to both mothers with University or College education $(\mathrm{M}=$ $3.51, \mathrm{SD}=0.91$ ) as well as those with at most secondary education $(\mathrm{M}=3.51, \mathrm{SD}=0.91 ; p$-value $=0.025)$. By the first month, this difference was no longer apparent and the mean scores of the three groups appear similar.

\section{Validity}

\section{Factor validity}

The construct validity of the BSES-SF was assessed in Exploratory Factor Analyses - see Table 2. The correlation matrix was adequate with the majority of the correlation coefficients exceeding 0.3. The KaiserMeyer-Olkin coefficient for sampling adequacy (KMO) was 0.96 , which is above the recommended value of 0.60 and the Bartlett's test of Sphericity was significant ( $p$ value $<0.001$ ), both suggesting that the data are appropriate for factor analysis. Based on the default criterion of eigenvalues greater than 1.0, the analysis yielded a one-factor solution even though the scree plot was suggestive of a two-dimensional structure.

Table 2 depicts the principal component analysis of the BSES scale. The first component included eight items, explaining $33.5 \%$ of the variance. With a few exceptions (e.g. "Tell when my baby is finished breastfeeding"), most items were more likely to tap on Breastfeeding Self-efficacy in terms of the cognitive aspects, such as "Keep wanting to breastfeed", "Comfortably breastfeed with my family members present" and "Deal with the fact that breastfeeding can be time-consuming". The second component included the remaining six items, and explained $32.5 \%$ of the variance. These were more likely to tap on the technical aspects of breastfeeding management. For example, "Determine that my baby is getting enough milk", "Ensure that my baby is properly latched on for the whole feeding" and "Manage to breastfeed even if my baby is crying". One of the items ("Finishing feeding my baby on one breast before switching to the other") cross-loaded in both components with similar factor loadings.

The tool appears to be tapping on two different aspects of breastfeeding self-efficacy. While these two aspects have been described previously in the literature, calculating an overall score seems to be the most standard approach. Thus, for comparability, the overall score was used for further analyses.

Table 2 Principal component analysis of the BSES-SF scale

\begin{tabular}{|c|c|c|c|}
\hline & I can always... & Component 1 & Component 2 \\
\hline 1 & Determine that my baby is getting enough milk & & 0.803 \\
\hline 2 & Successfully cope with breastfeeding like I have with other challenging tasks & & 0.763 \\
\hline 3 & Breastfeed my baby without using formula as a supplement & & 0.618 \\
\hline 4 & Ensure that my baby is properly latched on for the whole feeding & & 0.752 \\
\hline 5 & Manage the breastfeeding situation to my satisfaction & & 0.775 \\
\hline 6 & Manage to breastfeed even if my baby is crying & & 0.630 \\
\hline 7 & Keep wanting to breastfeed & 0.784 & \\
\hline 8 & Comfortably breastfeed with my family members present & 0.641 & \\
\hline 9 & Be satisfied with my breastfeeding experience & 0.721 & \\
\hline 10 & Deal with the fact that breastfeeding can be time-consuming & 0.788 & \\
\hline 11 & Finish feeding my baby on one breast before switching to the other breast & 0.574 & 0.512 \\
\hline 12 & Continue to breastfeed my baby for every feeding & 0.687 & \\
\hline 13 & Manage to keep up with my baby's breastfeeding demands & 0.653 & \\
\hline 14 & Tell when my baby is finished breastfeeding & 0.617 & \\
\hline \multicolumn{2}{|c|}{$\%$ of variance explained } & $58.5 \%$ & $7.48 \%$ \\
\hline \multicolumn{2}{|c|}{ Cronbach's alpha coefficient } & 0.923 & 0.911 \\
\hline
\end{tabular}




\section{Known-group validity}

According to Bandura, previous experiences have a significant influence on self-efficacy [12]. Thus, multiparous mothers with previous breastfeeding experience would be expected to be more likely to have higher BSES compared with primiparous mothers. A known-group comparison analysis was conducted to assess this assumption. As shown in Table 1, mothers with previous breastfeeding experience were more likely to report higher BSES $(\mathrm{M}=3.74, \mathrm{SD}=0.84)$ compared to both primiparas $(\mathrm{M}=3.17, \mathrm{SD}=0.81)$ as well as multiparas without $\mathrm{BF}$ experience $(\mathrm{M}=2.78, \mathrm{SD}=1.01 ;<0.001)$, who appear to have the lowest levels of breastfeeding selfefficacy, even compared to primiparas. The observed difference is statistically as well as clinically significant, as it represents a 0.7 SD difference in mean scores. This difference was still apparent at the first month after discharge.

In a stepwise linear regression analysis, parity along with intention to BF, initiation of BF, non-Cypriot background, vaginal delivery and tertiary, but not postgraduate, education were the only ones associated with BSES, explaining $24 \%$ of the variance $48 \mathrm{~h}$ postnatally - results not shown in a Table. In fact, parity $(\beta=0.414,95 \% \mathrm{CI}$ : $0.264,0.564 ; p$-value $=<0.001)$ and intention to EBF ( $\beta=0.642$, 95\% CI: $0.450-0.834 ; p$-value $<0.001$ ) showed the strongest associations with BSES. Other variables predictive of in-hospital BSES scores were initiation of BF $(\beta=0.498,95 \%$ CI: $0.133,0.862 ; p$-value $=0.008)$, non-Cypriot background $(\beta=0.422,95 \%$ CI: 0.240 , $0.604 ; p$-value $<0.001)$, vaginal delivery $(\beta=0.273 ; 95 \%$ CI: $0.120,0.427 ; p$-value $=0.001)$ and university, but not postgraduate, education ( $\beta=0.182$; 95\% CI: $0.022,0.342$; $p$-value $=0.026)$.

\section{Concurrent and predictive validity}

Concurrent and predictive validity of the scale was evaluated by assessing the differences in BSES scores according to breastfeeding initiation and status at $48 \mathrm{~h}$ and thereafter up to the sixth month of the infants' life. BSES scores during the first $48 \mathrm{~h}$ were highest among mothers who initiated exclusively breastfeeding while at the clinic $(\mathrm{M}=3.92, \mathrm{SD}=0.80)$ compared to those who were breastfeeding not exclusively $(\mathrm{M}=3.29, \mathrm{SD}=0.84)$ and those not breastfeeding $(\mathrm{M}=3.04, \mathrm{SD}=1.09 ; p$-value < 0.001 ) - see Table 3. A similar stepwise pattern of association with breastfeeding status and BSES scores was observed across all follow-up phases of the study, irrespective of whether the analysis looked at the in-hospital or the 1st month assessment of BSES. Consistently, mothers who were still exclusively breastfeeding at a specific time-point of investigation were those who reported higher on average BSES scores (in-hospital or at 1st month), with progressively lower mean scores
Table 3 In-hospital and 1st month BSES mean scores by breastfeeding status at $48 \mathrm{~h}$ and at first, fourth and sixth month

\begin{tabular}{llllll}
\hline \multicolumn{4}{l}{ Mean (SD) BSES-SF score } \\
\cline { 2 - 6 } $\mathrm{N}$ & $48 \mathrm{~h}$ & $p$-value $\neq$ & $\mathrm{N}$ & 1 st month & $p$-value $¥$ \\
\hline
\end{tabular}

\section{According to BF status}

At $48 \mathrm{~h}$

$\begin{array}{lllll}\text { EBF } & 104 & 3.92(0.80) & <0.001 & - \\ \text { BF } & 365 & 3.29(0.84) & - \\ \text { Non-BF } & 35 & 3.04(1.09) & -\end{array}$

\section{At 1st month}

$\begin{array}{lllllll}\text { EBF } & 58 & 3.85(0.86) & <0.001 & 64 & 4.39(0.66) & <0.001 \\ \text { BF } & 193 & 3.49(0.84) & & 206 & 3.95(0.75) & \\ \text { Non-BF } & 70 & 2.96(0.93) & & 14 & 3.23(0.74) & \end{array}$

\section{At 4th month}

$\begin{array}{llllllll}\text { EBF } & 45 & 3.96(0.67) & <0.001 & 40 & 4.45(0.54) & <0.001 \\ \text { BF } & 114 & 3.65(0.82) & & 105 & 4.29(0.65) & \\ \text { Non-BF } & 184 & 3.15(0.92) & & 111 & 3.60(0.80) & \\ \text { At 6th month } & & & & & \\ \text { EBF } & 18 & 3.90(0.76) & <0.001 & 19 & 4.55(0.35) & <0.001 \\ \text { BF } & 97 & 3.73(0.79) & & 88 & 4.32(0.62) & \\ \text { Non-BF } & 213 & 3.23(0.92) & & 142 & 3.71(0.81) & \end{array}$

$¥ p$-value of one-way ANOVA

observed among mother who were either breastfeeding but not exclusively or not breastfeeding by that point.

\section{Association of BSES with continuation and exclusivity of breastfeeding}

To investigate the association of BSES with BF status, we categorized participating mothers based on their BSES scores at $48 \mathrm{~h}$ and first month into quartiles. At $48 \mathrm{~h}$, for example, the lowest quartile includes the quarter of women with the lowest scores (range: 1.00-2.71) and the upper quartile, those with the highest scores (range: 4.07-5.00). While not large differences were observed in terms of initiation of breastfeeding according to BSES, as shown in Fig. 1, there appears to be a clear stepwise pattern of association of BSES with EBF and BF continuation up to the sixth month. For instance, among the quartile of mothers with the highest BSES scores, as many as $40 \%$ initiated exclusive breastfeeding during their stay at the maternity clinic. In contrast, among the quartile of mothers with the lowest BSES scores only $7.9 \%$ initiated EBF ( $p$-value $<0.001)$. The prevalence of EBF for the two middle groups appeared in-between with 15.1 and $19.0 \%$, respectively. At the first month, among mothers at the upper quartile of in-hospital BSES scores about three times as many as those in the lower quartile were exclusively breastfeeding ( $30.7 \%$ vs $10.4 \%)$ and about twice as many as those in the second and third quartile ( $30.7 \%$ vs $14.1 \%$ vs $15.4 \%$, respectively). 


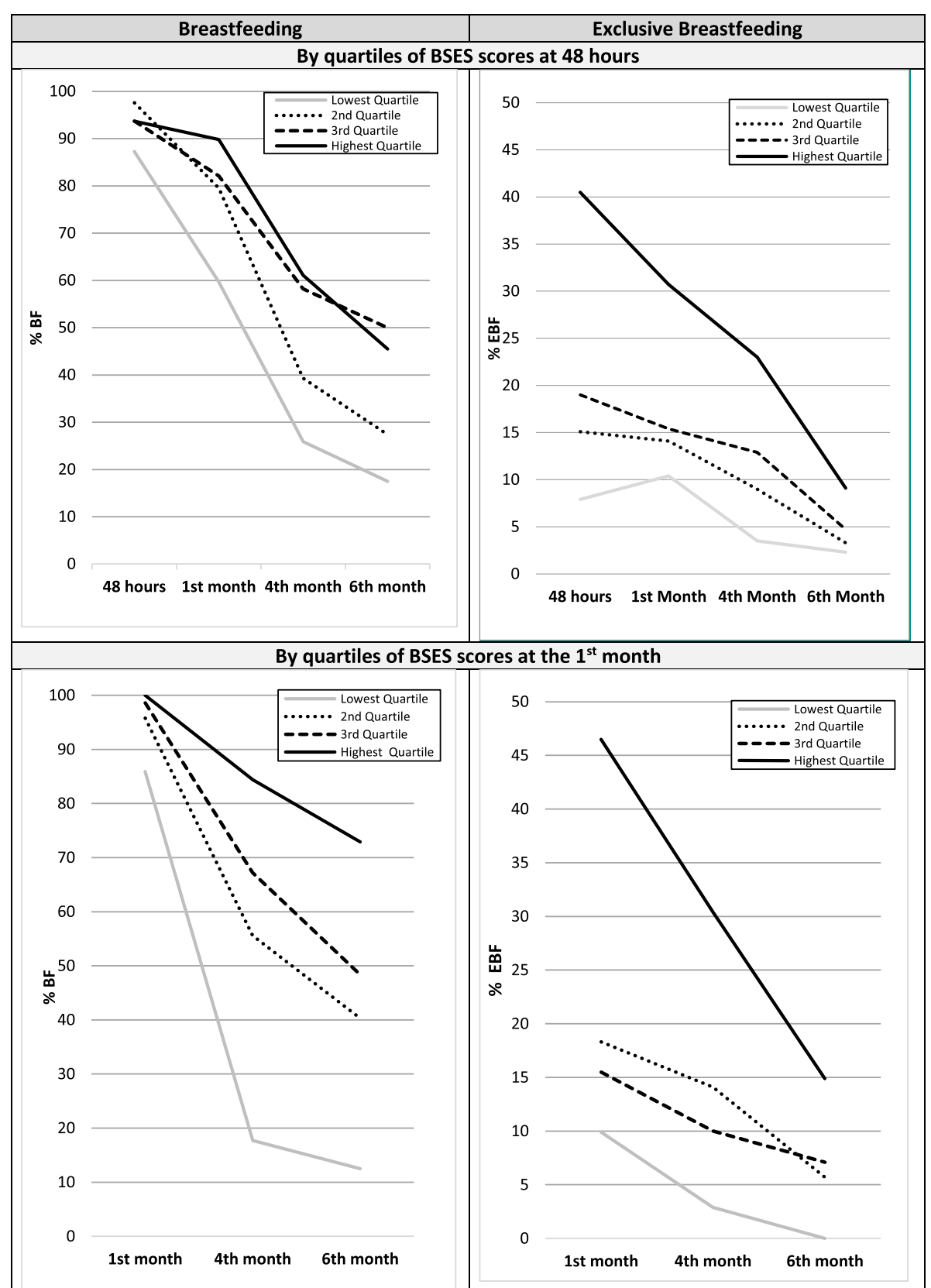

Fig. 1 Prevalence of breastfeeding and exclusive breastfeeding by quartiles of increasing BSES scores at $48 \mathrm{~h}$ and 1st month

Differences in the prevalence of EBF at the fourth month widened further and only appear to converge by the sixth month, due to a sharper decline in the prevalence of EBF among mothers with the highest in-hospital BSES scores. Similar stepwise patterns were observed when using BSES as reported at the first month to track BF and EBF continuation beyond the first month.

Table 4 presents the odds of BF and EBF according to quartiles of increasing levels of in-hospital or 1st-month BSES as estimated in multivariable logistic regression models. The clear stepwise pattern of association of BF outcomes with BSES irrespective of whether measured at $48 \mathrm{~h}$ or 1 st month is apparent even after adjusting for potential confounders such as parity, mode of delivery and social position. For instance, a stepwise increase was observed in the odds of EBF initiation as well as at all other timepoints across quartiles of women with increasing levels of BSES at $48 \mathrm{~h}$. Mothers in the second and third quartile were about two to three times more likely to initiate EBF compared to those in the lowest quartile, while the likelihood of women at the upper quartile to initiate exclusive breastfeeding is 8 -times higher $(\mathrm{OR}=$ 


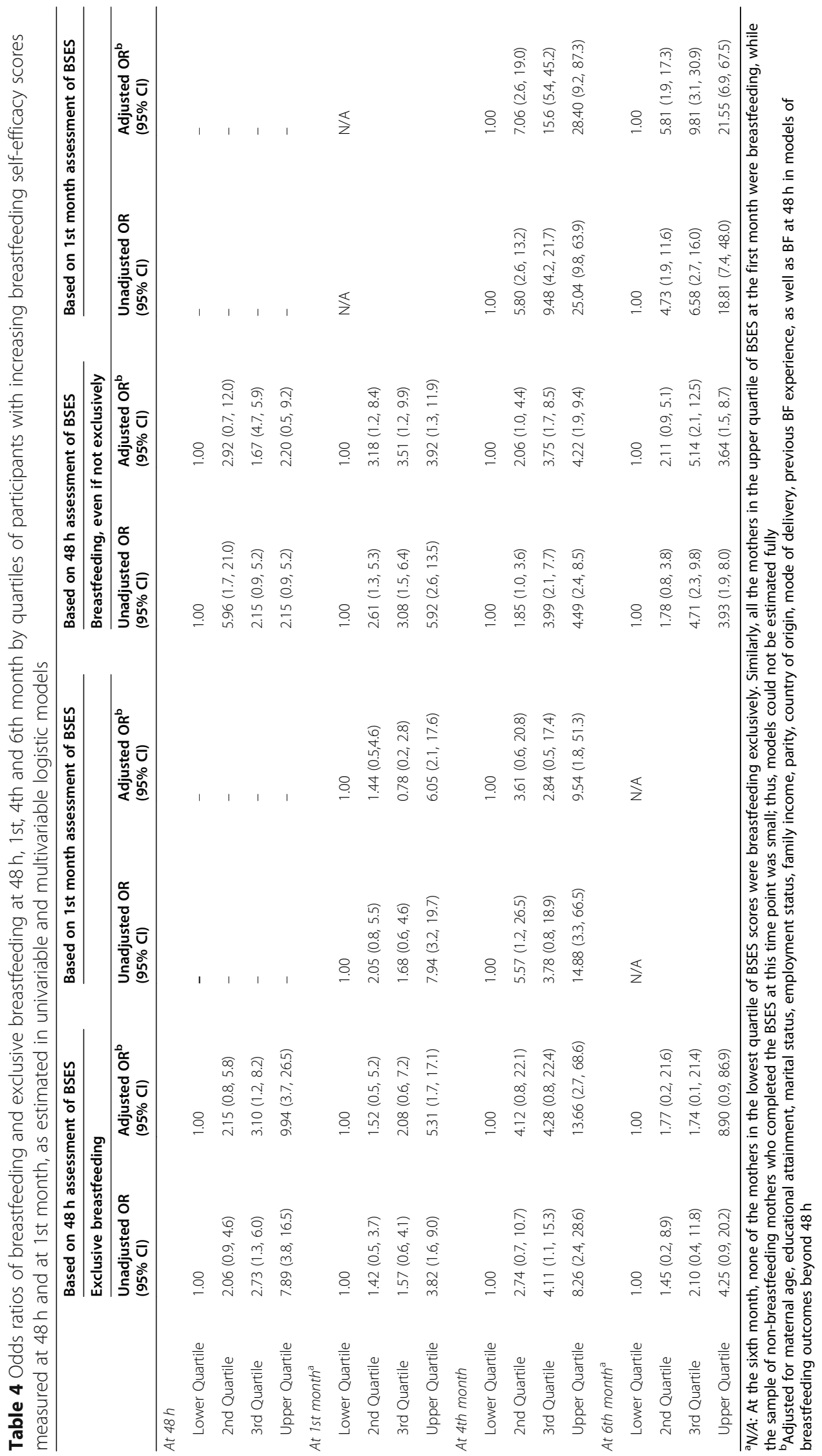


7.89, 95\% CI: 3.77-16.49; $p$-value< 0.001). In the multivariable model, the association appears even stronger with $\operatorname{adjOR}=9.94$ (95\% CI: $3.72-26.58 ; p$-value $<0.001$ ) in the upper quartile. In relation to EBF continuation, an association with BSES scores at $48 \mathrm{~h}$ was observed throughout the study period, attenuating slightly at the sixth month, possibly due to the small number of women exclusively breastfeeding by that point. Even though fewer than $10 \%$ of the mothers at the upper quartile were exclusively breastfeeding at the sixth month, this figure was still about four, three and two times higher compared to the respective figure observed among mothers at the lowest $(2.3 \%)$, the second (3.3\%) and the third quartile (4.7\%) of BSES scores respectively. The observed stepwise pattern across increasing quartiles of BSES appeared consistent at all time points of investigation irrespective of whether the analysis looked at 48-h or 1stmonth BSES scores.

\section{Diagnostic ability of the tool}

Table 5 shows the results of the ROC analysis for the predicting ability of the BSES - SF tool to identify mothers likely to successfully continue breastfeeding in the long term. In terms of diagnostic ability, the tool appears to perform better when used at the first month and less well when used at $48 \mathrm{~h}$ in terms of predicting BF continuation at 4th and 6th month. For instance, at a cut-off value of 3.96 (which appears to correspond to the highest quartile of scores as observed in this study), the Sensitivity and Specificity of the BSES-SF at 1st month for BF continuation at 4th month is 79.7 and $63.7 \%$, respectively. The positive and negative predictive value are 74.8 and $71.3 \%$, respectively.

\section{Discussion}

\section{Breastfeeding self-efficacy among mothers in Cyprus}

Against a generally low prevalence of breastfeeding among mothers in Cyprus, this study showed that low self-efficacy in the early period is associated with nonexclusivity and earlier discontinuation of breastfeeding. With a mean score of 3.55 (on a 1-5 scale), breastfeeding self-efficacy among women in Cyprus was only moderate. If expressed as a sum (instead of average) score, it corresponds to a score of 49.7 (theoretical range: $14-70)$. With a few exceptions [19, 25, 34], this is lower than what is commonly reported among other populations in the international literature using the same tool $(16-18,20,22,36]$.

\section{Dimensionality and internal consistency of the BSES-SF scale}

The observed internal consistency of the BSES-SF items was consistent with the original [16] as well as most similar studies in the literature. The BSES-SE seems to be tapping on two aspects of self-efficacy, namely breastfeeding technique and intrapersonal thoughts. Both the original study [16] as well as other translated versions of the scale $[17,18,20,22,34]$ identify the scale as unidimensional. Our findings are in agreement with a recently published study by Brandão et al. among Portuguese pregnant women which found a similar two-dimensional structure of the BSES-SF scale [35]. In that study, the second component explained only $7.6 \%$ of the variance, compared to $53.2 \%$ for the first component, whereas in the present study, the percentage of variance explained by the two components was more equally distributed.

\section{Concurrent and predictive validity of the BSES-SF}

As expected, large differences were observed in terms of in-hospital BSES-SF scores according to breastfeeding status, demonstrating the concurrent and predictive validity of the tool. This finding is not surprising and, with a few exceptions $[29,36]$, it is in agreement with the majority of previous studies. However, only a few studies investigated the association of BSES with BF/EBF up to the sixth month [19, 25-28, 36, 37] as studies commonly investigate the association of BSES with BF within shorter time periods [15, 30, 37-42]. Similar, if not even larger differences were observed between $\mathrm{BF} / \mathrm{EBF}$ and breastfeeding self-efficacy as reported at the 1st month, and this is also consistent with studies which measured BSES postnatally [19, 25, 27, 28, 36, 43].

Table 5 Receiver operating characteristics (ROC) analysis of breastfeeding continuation at 4th and 6th month as measured by the BSES-SF at $48 \mathrm{~h}$ and $1 \mathrm{st}$ month

\begin{tabular}{|c|c|c|c|c|c|c|}
\hline & \multicolumn{2}{|c|}{ Breastfeeding at 4th month } & \multicolumn{2}{|c|}{ Exclusive breastfeeding at 4th month ${ }^{\mathrm{a}}$} & \multicolumn{2}{|c|}{ Breastfeeding at 6 th month } \\
\hline & BSES at $48 \mathrm{~h}$ & BSES at 1st month & BSES at $48 \mathrm{~h}$ & BSES at 1st month & BSES at $48 \mathrm{~h}$ & BSES at 1st month \\
\hline AUC (SE) & $0.666(0.035)$ & $0.779(0.030)$ & $0.696(0.042)$ & $0.707(0.045)$ & $0.646(0.036)$ & $0.755(0.032)$ \\
\hline Optimal cut-off & 3.40 & 3.96 & 3.96 & 3.96 & 3.40 & 3.96 \\
\hline Sensitivity (\%) & 70.3 & 79.7 & 63.9 & 91.7 & 73.0 & 81.0 \\
\hline Specificity (\%) & 58.8 & 63.7 & 70.0 & 44.8 & 55.3 & 56.1 \\
\hline Positive predictive value (\%) & 59.7 & 74.8 & 24.6 & 22.4 & 48.0 & 58.9 \\
\hline Negative predictive value (\%) & 68.5 & 71.3 & 93.1 & 97.4 & 79.0 & 79.6 \\
\hline
\end{tabular}

${ }^{a}$ The number of mothers who breastfed exclusively at the 6th month was too small to allow meaningful estimation of the ROC model 
The ROC analysis showed that the in-hospital BSESSF scale at a cut-off value of 3.6 (corresponding to a sum score of 50.4) has acceptable diagnostic ability that a mother would still breastfeed at the 4th month and 6th month. A study by Ip et al. among Hong Kong Chinese mothers found that the BSES-SF at a cut-off value = 45.5 during hospital stay ( $48-72 \mathrm{~h}$ ) could be used as a screening tool to identify mothers most likely to discontinue breastfeeding before 6 months with $\mathrm{Sn}=73 \%, \mathrm{Sp}=$ $73 \%, \mathrm{PPV}=92 \%$ and $\mathrm{NPV}=42 \%$ [19]. In the present study, the predictive value of the scale appeared somewhat better when BSES was assessed at the first month, rather than within the first $48 \mathrm{~h}$. The sensitivity and specificity of the 1st month BSES-SF to identify breastfeeding continuation at 4 months were 79.7 and $63.7 \%$ respectively. The sensitivity of the 1 st month assessment for breastfeeding at 6 months is very good (81\%); however the specificity is average $(56.1 \%)$ but not surprising as only one in 20 women breastfeed exclusively at 6 months. The positive predictive value of a relatively high score at the first month is 74.8 and $58.9 \%$ for breastfeeding at the 4th and 6th month respectively. Thus, one in four and one in two women with high scores will be false positives, and they will discontinue breastfeeding suggesting that several other factors are at play. In terms of the negative predictive value, it is encouraging that a relatively low BSES score at the first month will correctly identify 63.7 and $56.1 \%$ of the women who will discontinue breastfeeding by the 4th and 6th month respectively.

\section{Sociodemographic characteristics and breastfeeding self- efficacy}

No differences were observed in in-hospital breastfeeding self-efficacy in relation to maternal demographic characteristics $[16-18,22,23,31]$, with the exception of educational attainment. In fact, mothers with postgraduate education appear to have the lowest breastfeeding self-efficacy levels. This comes in contrast with other findings that suggest a positive relationship between breastfeeding self-efficacy and maternal education [18]. This association diminished by the first month. This may suggest that mothers with higher education are more likely to be aware of the difficulties risen during $\mathrm{BF}$ initiation which might result to negative beliefs towards their perceived ability to initiate $\mathrm{BF}$, but are more likely to seek support and overcome the challenges in the long run. In fact, this is consistent with the fact that mothers with postgraduate education appear to have the largest increase in breastfeeding self-efficacy between the two time-points. This also appears consistent with the finding, that, even though there was no difference in the likelihood to initiate exclusive breastfeeding according to educational attainment, in the long term those with the highest educational attainment were 1.8-times (1st month), 2.3-times (4th month) and 3.7-times (6th month) more likely to be exclusively breastfeeding compared to mothers with primary or secondary education - results not shown in detail. It is also interesting to note that Cypriot women appear to have lower on average breastfeeding self-efficacy than non-Cypriot women. The extent to which this is reflective of differences in breastfeeding culture or other breastfeeding determinants between the two groups is not clear. Consistent with previous studies $[15,44-48]$, mothers with previous breastfeeding experience are more likely to report higher breastfeeding self-efficacy. This results in a higher likelihood of successful BF initiation, continuation and exclusivity $[15,45,49]$. However, there is evidence to suggest that a negative or neutral previous experience may affect breastfeeding self-efficacy negatively [50]. This study did not explore the characteristics of the previous or current experience, which may determine the continuation of the behaviour [51, 52].

Intention to breastfeed was also associated with breastfeeding self-efficacy $[45,48]$. This might be explained by the fact that mothers that intent to BF are more likely to be aware about the benefits of exclusive breastfeeding, had attended antenatal educational sessions [48] and seeked formal or informal support [48, 53]. In a recent study, Kronborg et al. found that both intention and self-efficacy are significant mediators of EBF and BF duration even among second-time mothers. It is interesting to note that in this study, even though the actual prevalence of exclusive breastfeeding was only $18.8 \%$ at $48 \mathrm{~h}$, $73.2 \%$ of mothers reported their intention to breastfeed exclusively [54]. The present study also confirmed the association between breastfeeding self-efficacy and mode of delivery, with mothers who gave birth vaginally having higher levels of breastfeeding self-efficacy [16, 45, 55]. There is evidence to suggest that intention to breastfeed is lower among mothers who give birth by C/S [56]. Furthermore, there is evidence to suggest that women who give birth by $\mathrm{C} / \mathrm{S}$ are less likely to experience or request the implementation of "good practices" [57]. Experience of the "10 Steps to Successful Breastfeeding" are thought to facilitate the development of breastfeeding skills [58] and thereafter the strengthening of breastfeeding selfefficacy [50, 55], which in turn strengthens maternal commitment to breastfeed [59]. In addition, women who deliver by $\mathrm{C} / \mathrm{S}$ are more likely to experience breastfeeding difficulties [56] including latching difficulties, perceived lack of infant satiation and perceived lack of infant interest towards breastfeeding [60]. Early BF initiation within $1 \mathrm{~h}$ after birth [50], skin-to-skin [61] and rooming-in [50], all of which there is evidence to suggest are not widely implemented in Cyprus [8] have all been positively associated with higher breastfeeding self- 
efficacy levels. This is consistent with the finding that women who had a C/S without general anesthesia have somewhat higher levels of breastfeeding self-efficacy than those that gave birth with general anesthesia.

\section{Strengths and limitations}

This is the first study to evaluate the psychometric properties of the Greek version of the BSES-SF and describe the breastfeeding self-efficacy of women giving birth in Cyprus. A clear strength is the longitudinal design which facilitated the assessment of feeding practices over the first 6 months, as an indicator of the predictive validity of the tool, avoiding the recall bias of a retrospective design. In fact, it is among a few studies that measured the predictive validity of BSES measured on two occasions on BF duration and exclusivity up to the sixth month, suggesting that the BSES -SF can be a useful tool for the identification of mothers who are more likely to succeed their breastfeeding goal. Even though a number of private clinics opted to self-exclude from the study, the generalizability of findings, at least in a national context, is supported by the fact that the sample is largely representative of the cohort of mothers giving birth in Cypriot maternity clinics. With a response rate of $73.5 \%$ at baseline and $63.5 \%$ at follow-up, selection bias cannot be ruled out and it is likely that women who intended to breastfeed might be overrepresented in the sample. Even so, the prevalence of exclusive breastfeeding was particularly low while the observed variability in BSES scores among mothers in Cypriot maternity clinics is within the range, if not somewhat higher, than the variability observed in populations elsewhere, since a SD of 0.85 (on a 1-5 scale) corresponds to a SD of 12 on a $14-70$ scale. It is also acknowledged that the association between BF and BFSE is likely to be bidirectional (i.e. successful BF establishment positively influences BFSE in the longrun). Like previous similar studies, this study looked at the extent to which BSES is predictive of breastfeeding outcomes in the long term. Ever though the literature is limited with regard to the potential bidirectional association between BF and BSES, there is evidence to suggest that successful early initiation of $\mathrm{BF}$ within the first hour after birth, when acknowledged as a positive personal experience, might be associated with higher BFSE levels at first week postpartum [50]. Finally, intention to breastfeed was measured only with a singleitem and other potential covariates related to motivation (e.g. beliefs and attitudes related to breastfeeding, maternal personality characteristics, etc) have not been considered.

\section{Implications for research and practice}

In line with the aims, this study used only quantitative methods to explore breastfeeding self-efficacy and subsequent breastfeeding outcomes. However, future studies should focus on an in-depth exploration of the perceptions and attitudes of women in Cyprus with regards to breastfeeding, and perceived reasons for premature discontinuation using qualitative methods. Further research is also required to disentangle the bidirectional association of BSE and BF since personal experience of $\mathrm{BF}$, and the extent to which this is negative or positive, is likely to be the most important source of self-efficacy. A systematic and structured assessment of BSES is not standard practice while the mother is at the clinic, let alone after discharge since in Cyprus there is no continuation of care in the postnatal period. As this study suggests, the BSES could be adopted in clinical practice as a screening tool to facilitate the identification of the mothers at higher risk to discontinue breastfeeding prematurely. However, for this to be effective, it is important to reconsider the current structure of maternal health care services in the community, either through the widening of existing roles or the establishment of new roles such as Community Midwifery. Future research should be focused on the development and the evaluation of breastfeeding community support programmes which aim to enhance maternal breastfeeding self-efficacy. These programmes could include both formal and peer mother-to-mother support groups [6264]. A number of intervention studies have been designed based on self-efficacy theory and/or investigated the effect of breastfeeding education and/or support programmes explicitly through the enhancement of selfefficacy $[65,66]$. For instance, a pre- and post-test experimental study with the participation of 74 Chinese primiparas [65], showed significant differences in BSES between the intervention and the control group at 4 and 8 weeks after birth, while enhancement of BSES in this period was found to be significantly higher in the intervention group. The study showed that the positive impact of the intervention on BF duration and exclusivity, was mediated by the enhancement of BSES. However, a number of breastfeeding self-efficacy studies did not show a positive effect on breastfeeding outcomes [67] or the observed effect was short of statistical significance $[68,69]$.

As in many European countries, Cyprus has developed mechanisms and initiatives for the support, protection and promotion of $\mathrm{BF}$, including $\mathrm{BF}$ policies and strategies [70]. However, it has not yet proceeded to their full integration, implementation or harmonization within the national health system, resulting to the lack of effective breastfeeding promotion actions. Even though the Cyprus Ministry of Health has launched a call for the Baby Friendly Initiative, through the National Breastfeeding Committee, up to date, no hospital, public or private, in Cyprus has moved along with the Baby 
friendly initiative certification process. Originally a number of clinics had expressed an interest and promoted their intention publicly, a long time has ensued since the original call. This has recently led the National Breastfeeding Committee to assign to an ad hoc committee of practitioners and academics the task of designing the methodology and developing the necessary resources in order to move the process along and support interested hospitals in the process (personal communication). In the meantime, the fragmented implementation of the "10 Steps for Successful Breastfeeding" [8] and in particular the lack of institutionalized community support for breastfeeding mothers (corresponding to Step 10) continue to sustain conditions not contusive to promoting breastfeeding.

\section{Conclusions}

The Greek version of the BSES-SF showed good metric properties and it can be considered a valid and reliable measure of breastfeeding self-efficacy among new mothers in Cyprus. Concurrent and predictive validity of the scale was supported by the observed association of BSES with breastfeeding exclusivity at $48 \mathrm{~h}$ and with breastfeeding outcomes at the first, fourth and sixth month of the infants' life. The adoption of the BSES scale as a screening tool in clinical and community practice will assist in the targeted identification of women at higher risk for premature BF discontinuation. The generally low prevalence of breastfeeding among mothers in Cyprus and the absence of institutionalized breastfeeding community support programmes suggest the wider need for the design and evaluation of interventions beyond those focusing on the implementation of the Babyfriendly initiatives "10 steps" with a particular focus on theory-driven and researcher-informed community support interventions based on self-efficacy theory.

\section{Abbreviations}

BF: Breastfeeding; BSES: Breastfeeding self-efficacy; BSES-SF: Breastfeeding self-efficacy short form; EBF: Exclusive breastfeeding; C/S: Cesarean Section

\section{Supplementary Information}

The online version contains supplementary material available at https:/doi. org/10.1186/s12884-021-03878-3.

Additional file 1. Questions about breastfeeding self-efficacy/ confidence.

\section{Acknowledgements \\ We would to express our appreciation and gratitude to all mothers who participated in the study and well as to the field workers for their essential contribution for the recruitment of participants at the maternity clinics and data collection at the baseline phase of the study. Furthermore, we would like to acknowledge the National Breastfeeding Committee for their support.}

\section{Authors' contributions}

NM, IPD, OK, CK, EL and EH conceived and designed the study and secured the funding. IPD was the project leader and NM was the scientific coordinator of the BrEaST start in life programme. ME was the study's research coordinator and the study forms part of her doctoral dissertation. NM was the main PhD advisor of the first author (ME) and CK and EL were members of the PhD advisory committee and were all involved in the overall supervision of the study. $\mathrm{NM}, \mathrm{VH}$ and $\mathrm{ME}$ trained the field workers and monitored the data collection at phase I. VH and FT performed data collection at phase I of the study and contributed to data management and analysis and to the editing of the manuscript. ME conducted the telephone follow-up data collection at phase II, managed the dataset, performed the statistical analysis and wrote the first draft of the manuscript. NM guided the statistical analysis and NM and OK assisted in drafting and editing the first draft of the manuscript. All authors assisted in interpreting the data and critically revised the manuscript. All authors have read and approved the final version of the manuscript.

\section{Funding}

The study was part of the research program "The BrEaST start in life: addressing social inequalities and supporting breastfeeding through inclusion activities", which was funded by Iceland, Liechtenstein, and Norway through the EEA Financial Mechanism and the Republic of Cyprus. The funders played no part in any of the stages of the study including study design, collection, analysis and interpretation of data and in writing the manuscript.

\section{Availability of data and materials}

The datasets generated or analyzed during the study are not publicly available because data analysis is still ongoing.

\section{Declarations}

Ethics approval and consent to participate

Ethics approval was obtained from the Cyprus National Bioethics Committee (EEВK ЕП.2014.01.75). The Research Promotion Committee of the Ministry of Health (5.34.01.7.2E) also approved the study. Written consent was obtained for all participants at each phase of the study.

\section{Consent for publication}

Not Applicable

Competing interests

The authors declare no competing interests.

\section{Author details}

${ }^{1}$ Department of Nursing, School of Health Sciences, Cyprus University of Technology, Limassol, Cyprus. ${ }^{2}$ St George University of London Medical School at the University of Nicosia, Nicosia, Cyprus. ${ }^{3}$ Cyprus Breastfeeding Association - 'Gift for Life', Nicosia, Cyprus.

Received: 23 July 2020 Accepted: 13 May 2021

Published online: 09 June 2021

\section{References}

1. American Academy of Pediatrics. Breastfeeding and the use of human Milk. Pediatrics. 2012;129:e827-41.

2. Horta BL, Victora CG. Long-term effects of breastfeeding: a systematic review. Geneva: World Health Organization; 2013.

3. Kramer M., Kamuma P. The optimal duration of exclusive beastfeeding (review). The Cochrane Collaboration. 2012. http://cochranelibrarywiley.com/ doi/10.1002/14651858.CD003517.pub2/pdf. Accessed May 2020.

4. Black R, Victora C, Walker S, Bhutta Z, Christian P, de Onis M, et al. Maternal and child undernutrition and overweight in low-income and middleincome countries. Lancet. 2013;382(9890):427-51. https://doi.org/10.1016/ S0140-6736(13)60937-X.

5. Victora CG, Bahl R, Barros AJ, França GV, Horton S, Krasevec J, et al. Breastfeeding in the 21st century: epidemiology, mechanisms, and lifelong effect. Lancet. 2016;387(10017):475-90. https://doi.org/10.1016/S0140-6736(1 5)01024-7.

6. Rito, A. I., Buoncristiano, M., Spinelli, A., Salanave, B., Kunešová, M., Hejgaard,

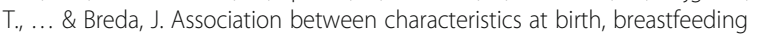
and obesity in 22 countries: the WHO European childhood obesity surveillance initiative-COSI 2015/2017. Obes Facts. 2019;12(2), 226-243.2. 
7. Ministry of Health. Cyprus maternity units: perinatal health indicators for the years of 2007-2009 compared to the European perinatal health report for year 2004. 2010. http://www.europeristat.com/images/doc/NPHR/cyprus_ perinatal_health_data_for_public_sector_maternity_units_cyprus.pdf. Accessed May 2017.

8. Hadjiona V, Middleton N, Kouta C, Hadjigeorgiou E, Lambrinou E, Kolokotroni O. Cyprus mothers ' breast feeding self-efficacy and their perceptions about the implementation of the '10 steps' in the first 48 hours after birth. Midwifery. 2016;36:43-52. https://doi.org/10.1016/j.midw.2016.02.021.

9. Economou M, Kolokotroni O, Paphiti-Demetriou I, Kouta C, Lambrinou E, Hadjigeorgiou $\mathrm{E}$, et al. Prevalence of breast-feeding and exclusive breastfeeding at $48 \mathrm{~h}$ after birth and up to the sixth month in Cyprus: the BrEaST start in life project. Public Health Nutr. 2018;21(5):967-80. https://doi.org/1 $0.1017 /$ S1368980017003214.

10. Dennis CL, Faux S. Development and psychometric testing of the breastfeeding self-efficacy scale. Res Nurs Health. 1999;22(5):399-409. https:// doi.org/10.1002/(SICI) 1098-240X(199910)22:5<399::AID-NUR6>3.0.CO;2-4.

11. Blyth RJ, Creedy DK, Dennis CL, Moyle W, Pratt J, De Vries SM, et al. Breastfeeding duration in an Australian population: the influence of modifiable antenatal factors. J Hum Lact. 2004;20(1):30-8. https://doi.org/1 $0.1177 / 0890334403261109$

12. Bandura A. Self-efficacy: toward a unifying theory of behavioral change. Psychol Rev. 1977;84(2):191-215. https://doi.org/10.1037/0033-295X.84.2.191.

13. Dennis CL. Theoretical underpinnings of breastfeeding confidence: a selfefficacy framework. J Hum Lact. 1999;15(3):195-201. https://doi.org/10.1177/ 089033449901500303.

14. Bandura A. Self-efficacy. Encyclopedia of human behavior; 1994. p. 71-81.

15. Hinic K. Predictors of breastfeeding confidence in the early postpartum period. J Obstet Gynecol Neonatal Nurs. 2016;45(5):649-60. https://doi.org/1 0.1016/j.jogn.2016.04.010

16. Dennis CL. The breastfeeding self- efficacy scale: psychometric assessment of the short form. J Obstet Gynecol Neonatal Nurs. 2003;32(6):734-44. https://doi.org/10.1177/0884217503258459.

17. Wutke K, Dennis CL. The reliability and validity of the polish version of the breastfeeding self-efficacy scale-short form: translation and psychometric assessment. Int J Nurs Stud. 2007;44(8):1439-46. https://doi.org/10.1016/j. ijnurstu.2006.08.001.

18. Pavicic Bosnjak A, Rumboldt M, Stanojevic M, Dennis CL. Psychometric assessment of the Croatian version of the breastfeeding self-efficacy scaleshort form. J Hum Lact. 2012;28(4):565-9. https://doi.org/10.1177/ 0890334412456240.

19. Ip WY, Yeung LS, Choi KC, Chair SY, Dennis CL. Translation and validation of the Hong Kong Chinese version of the breastfeeding self- efficacy scale-short form. Res Nurs Health. 2012;35(5):450-9. https://doi.org/10.1002/nur.21493.

20. Tokat MA, Okumuş H, Dennis CL. Translation and psychometric assessment of the breast-feeding self-efficacy scale-short form among pregnant and postnatal women in Turkey. Midwifery. 2010;26(1):101-8. https://doi.org/10.1 016/j.midw.2008.04.002.

21. Gerhardsson $\mathrm{E}$, Nyqvist $\mathrm{KH}$, Mattsson $\mathrm{E}$, Volgsten $\mathrm{H}$, Hildingsson I, Funkquist EL. The Swedish version of the breastfeeding self-efficacy scale-short form: reliability and validity assessment. J Hum Lact. 2014;30(3):340-5. https://doi. org/10.1177/0890334414523836.

22. Zubaran $C$, Foresti $K$, Schumacher M, Thorell MR, Amoretti A, Müller $L$, et al. The Portuguese version of the breastfeeding self-efficacy scale-short form. J Hum Lact. 2010;26(3):297-303. https://doi.org/10.1177/0890334409359916.

23. Oliver-Roig A, d'Anglade-González ML, García-García B, Silva-Tubio JR, Richart-Martínez M, Dennis CL. The Spanish version of the breastfeeding self- efficacy scale-short form: reliability and validity assessment. Int J Nurs Stud. 2012:49(2):169-73. https://doi.org/10.1016/j.ijnurstu.2011.08.005.

24. Dennis CL, Heaman M, Mossman M. Psychometric testing of the breastfeeding self-efficacy scale-short form among adolescents. J Adolesc Health. 2011;49(3):265-71. https://doi.org/10.1016/j.jadohealth.2010.12.015.

25. Semenic S, Loiselle C, Gottlieb L. Predictors of the duration of exclusive breastfeeding among first- time mothers. Res Nurs Health. 2008;31(5):42841. https://doi.org/10.1002/nur.20275.

26. Wilhelm SL, Rodehorst TK, Stepans MBF, Hertzog M, Berens C. Influence of intention and self-efficacy levels on duration of breastfeeding for midwest rural mothers. Appl Nurs Res. 2008;21(3):123-30. https//doi.org/10.1016/j.apnr.2006.10.005.

27. Tsai TI, Huang SH, Lee SYD. Maternal and hospital factors associated with first-time mothers' breastfeeding practice: a prospective study. Breastfeed Med. 2015;10(6):334-40. https://doi.org/10.1089/bfm.2015.0005.
28. McCarter-Spaulding DE, Dennis CL. Psychometric testing of the breastfeeding self- efficacy scale- short form in a sample of black women in the United States. Res Nurs Health. 2010;33(2):111-9. https://doi.org/10.1 002/nur.20368.

29. Gregory A, Penrose K, Morrison C, Dennis CL, MacArthur C. Psychometric properties of the breastfeeding self- efficacy scale- short form in an ethnically diverse UK sample. Public Health Nurs. 2008;25(3):278-84. https:// doi.org/10.1111/j.1525-1446.2008.00705.x.

30. McQueen K, Sieswerda LE, Montelpare W, Dennis CL. Prevalence and factors affecting breastfeeding among aboriginal women in northwestern Ontario. J Obstet Gynecol Neonatal Nurs. 2015;44(1):51-68. https://doi.org/10.1111/1552-6909.12526.

31. Glassman ME, McKearney K, Saslaw M, Sirota DR. Impact of breastfeeding self-efficacy and sociocultural factors on early breastfeeding in an urban, predominantly Dominican community. Breastfeed Med. 2014;9(6):301-7. https://doi.org/10.1089/bfm.2014.0015.

32. Boateng GO, Martin SL, Tuthill EL, Collins SM, Dennis CL, Natamba BK, et al. Adaptation and psychometric evaluation of the breastfeeding self-efficacy scale to assess exclusive breastfeeding. BMC Pregnancy Childbirth. 2019; 19(1):73. https://doi.org/10.1186/s12884-019-2217-7.

33. UNICEF/WHO BFHI. Baby friendly hospital initiative. Revised version updated and expanded for integrated care. Chapter 4-Self Assessment and Monitoring of the Hospital. 2006. https://www.unicef.org/nutrition/files/ BFHI_2009_s4.pdf. Accessed Mar 2017.

34. Iliadou M, Lykeridou K, Prezerakos P, Zyga S, Sakellari E, Vivilaki V, et al. Psychometric properties of the Greek version of the breastfeeding selfefficacy scale and correlation with depressive symptomatology. Arch Hell Med. 2020;37(5):656-62.

35. Brandão S, Mendonça D, Dias CC, Pinto TM, Dennis CL, Figueiredo B. The breastfeeding self-efficacy scale-short form: psychometric characteristics in Portuguese pregnant women. Midwifery. 2018;66:49-55. https://doi.org/10.1 016/j.midw.2018.07.014.

36. Baghurst P, Pincombe J, Peat B, Henderson A, Reddin E, Antoniou G. Breast feeding self-efficacy and other determinants of the duration of breast feeding in a cohort of first-time mothers in Adelaide, Australia. Midwifery. 2007;23(4):382-91. https://doi.org/10.1016/j.midw.2006.05.004.

37. Ku CM, Chow SK. Factors influencing the practice of exclusive breastfeeding among Hong Kong Chinese women: a questionnaire survey. J Clin Nurs. 2010;19(17-18):2434-45. https://doi.org/10.1111/j.1365-2702.2010.03302.x.

38. Zubaran C, Foresti K. The correlation between breastfeeding self-efficacy and maternal postpartum depression in southern Brazil. Sex Reprod Healthc. 2013;4(1):9-15. https://doi.org/10.1016/j.srhc.2012.12.001.

39. Loke AY, Chan LKS. Maternal breastfeeding self- efficacy and the breastfeeding behaviors of newborns in the practice of exclusive breastfeeding. J Obstet Gynecol Neonatal Nurs. 2013;42(6):672-84. https:// doi.org/10.1111/1552-6909.12250.

40. Yu EA, Thomas JS, Owais A, Tirmizi N, Faruque ASG, Das SK, et al. Maternal prenatal attitudes and postnatal breast-feeding behaviours in rural Bangladesh. Public Health Nutr. 2014;18(4):679-85. https://doi.org/10.1017/ S1368980014000937.

41. Linares AM, Rayens MK, Dozier A, Wiggins A, Dignan MB. Factors influencing exclusive breastfeeding at 4 months postpartum in a sample of urban Hispanic mothers in Kentucky. J Hum Lact. 2015;31(2):307-14. https://doi. org/10.1177/0890334414565711.

42. Petrozzi A, Gagliardi L. Breastfeeding self-efficacy scale: validation of the Italian version and correlation with breast-feeding at 3 months. J Pediatr Gastroenterol Nutr. 2016;62(1):137-9. https://doi.org/10.1097/MPG. 0000000000000902.

43. O'Brien M, Buikstra E, Hegney D. The influence of psychological factors on breastfeeding duration. J Adv Nurs. 2008;63(4):397-408. https://doi.org/1 0.1111/j.1365-2648.2008.04722.x.

44. Otsuka K, Dennis CL, Tatsuoka H, Jimba M. The relationship between breastfeeding self- efficacy and perceived insufficient milk among Japanese mothers. J Obstet Gynecol Neonatal Nurs. 2008;37(5):546-55. https://doi. org/10.1111/j.1552-6909.2008.00277.x.

45. Dennis CLE. Identifying predictors of breastfeeding self- efficacy in the immediate postpartum period. Res Nurs Health. 2006;29(4):256-68. https:// doi.org/10.1002/nur.20140.

46. Ingram J. A mixed methods evaluation of peer support in Bristol, UK: mothers', midwives' and peer supporters' views and the effects on breastfeeding. BMC Pregnancy Childbirth. 2013;13(1):192. https://doi.org/1 0.1186/1471-2393-13-192. 
47. Zhu J, Chan WCS, Zhou X, Ye B, He HG. Predictors of breast feeding selfefficacy among Chinese mothers: a cross-sectional questionnaire survey. Midwifery. 2014;30(6):705-11. https://doi.org/10.1016/j.midw.2013.12.008.

48. Yang X, Gao LL, Ip WY, Chan WCS. Predictors of breast feeding self-efficacy in the immediate postpartum period: a cross-sectional study. Midwifery. 2016:41:1-8. https://doi.org/10.1016/j.midw.2016.07.011.

49. Wells KJ, Thompson NJ, Kloeblen-Tarver AS. Development and psychometric testing of the prenatal breast-feeding self-efficacy scale. Am J Health Behav. 2006;30(2):177-87. https://doi.org/10.5993/AJHB.30.2.7.

50. Koskinen KS, Aho AL, Hannula L, Kaunonen M. Maternity hospital practices and breast feeding self-efficacy in Finnish primiparous and multiparous women during the immediate postpartum period. Midwifery. 2014;30(4): 464-70. https://doi.org/10.1016/j.midw.2013.05.003.

51. Palmér L, Carlsson G, Mollberg M, Nyström M. Severe breastfeeding difficulties: existential lostness as a mother-Women's lived experiences of initiating breastfeeding under severe difficulties. Int J Qual Stud Health Well Being. 2012;7(1):10846. https://doi.org/10.3402/qhw.v7i0.10846.

52. Thulier D, Mercer J. Variables associated with breastfeeding duration. J Obstet Gynecol Neonatal Nurs. 2009;38(3):259-68. https://doi.org/10.1111/j.1 552-6909.2009.01021.x.

53. Mannion CA, Hobbs AJ, McDonald SW, Tough SC. Maternal perceptions of partner support during breastfeeding. Int Breastfeed J. 2013;8(1):4. https:// doi.org/10.1186/1746-4358-8-4.

54. Kronborg H, Foverskov E, Væth M, Maimburg RD. The role of intention and self-efficacy on the association between breastfeeding of first and second child, a Danish cohort study. BMC Pregnancy Childbirth. 2018;18(1):454. https://doi.org/10.1186/s12884-018-2086-5.

55. Ngo LTH, Chou HF, Gau ML, Liu CY. Breastfeeding self-efficacy and related factors in postpartum Vietnamese women. Midwifery. 2019;70:84-91. https://doi.org/10.1016/j.midw.2018.12.014

56. Hobbs AJ, Mannion CA, McDonald SW, Brockway M, Tough SC. The impact of caesarean section on breastfeeding initiation, duration and difficulties in the first four months postpartum. BMC Pregnancy Childbirth. 2016;16(1):90. https://doi.org/10.1186/s12884-016-0876-1.

57. Merten S, Dratva J, Ackermann-Liebrich P. Do baby-friendly hospitals influence breastfeeding duration on a national level? Pediatrics. 2005;116(5): e702-8. https://doi.org/10.1542/peds.2005-0537.

58. Buxton KE, Gielen AC, Faden RR, Brown CH, Paige DM, Chwalow AJ. Women intending to breastfeed: predictors of early infant feeding experiences. Am J Prev Med. 1991;7(2):101-6. https://doi.org/10.1016/S0749-3797(18)30945-0.

59. Avery A, Zimmermann K, Underwood PW, Magnus JH. Confident commitment is a key factor for sustained breastfeeding. Birth. 2009;36(2): 141-8. https://doi.org/10.1111/j.1523-536X.2009.00312.x.

60. Tully KP, Ball HL. Maternal accounts of their breast-feeding intent and early challenges after caesarean childbirth. Midwifery. 2014;30(6):712-9. https:// doi.org/10.1016/j.midw.2013.10.014.

61. Aghdas K, Talat K, Sepideh B. Effect of immediate and continuous motherinfant skin-to-skin contact on breastfeeding self-efficacy of primiparous women: a randomised control trial. Women Birth. 2014;27(1):37-40. https:// doi.org/10.1016/j.wombi.2013.09.004.

62. Renfrew MJ, McCormick FM, Wade A, Quinn B, Dowswell T. Support for healthy breastfeeding mothers with healthy term babies. Cochrane Database Syst Rev. 2012;5(5):1-121.

63. McFadden A, Gavine A, Renfrew MJ, Wade A, Buchanan P, Taylor JL, et al. Support for healthy breastfeeding mothers with healthy term babies. Cochrane Libr. 2017;(2):1-237.

64. Phillips R, Copeland L, Grant A, Sanders J, Gobat N, Tedstone S, et al. Development of a novel motivational interviewing (MI) informed peer-support intervention to support mothers to breastfeed for longer. BMC Pregnancy Childbirth. 2018;18(1):90. https://doi.org/10.1186/s12884-018-1725-1.

65. Wu DS, Hu J, McCoy TP, Efird JT. The effects of a breastfeeding self- efficacy intervention on short- term breastfeeding outcomes among primiparous mothers in Wuhan, China. J Adv Nurs. 2014;70(8):1867-79. https://doi.org/1 0.1111/jan.12349.

66. Chan MY, Ip WY, Choi KC. The effect of a self-efficacy-based educational programme on maternal breast feeding self-efficacy, breast feeding duration and exclusive breast feeding rates: a longitudinal study. Midwifery. 2016:36:92-8. https://doi.org/10.1016/j.midw.2016.03.003.

67. Noel-Weiss J, Rupp A, Cragg B, Bassett V, Woodend AK. Randomized controlled trial to determine effects of prenatal breastfeeding workshop on maternal breastfeeding self-efficacy and breastfeeding duration. J Obstet
Gynecol Neonatal Nurs. 2006;35(5):616-24. https://doi.org/10.1111/j.15526909.2006.00077.x

68. Nichols J, Schutte NS, Brown RF, Dennis CL, Price I. The impact of a selfefficacy intervention on short-term breast-feeding outcomes. Health Educ Behav. 2009;36(2):250-8. https://doi.org/10.1177/1090198107303362.

69. McQueen KA, Dennis CL, Stremler R, Norman CD. A pilot randomized controlled trial of a breastfeeding self- efficacy intervention with primiparous mothers. J Obstet Gynecol Neonatal Nurs. 2011;40(1):35-46. https://doi.org/10.1111/j.1552-6909.2010.01210.x

70. Theurich MA, Davanzo R, Busck-Rasmussen M, Díaz-Gómez NM, Brennan C,

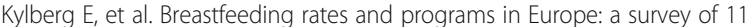
national breastfeeding committees and representatives. J Pediatr Gastroenterol Nutr. 2019;68(3):400-7. https://doi.org/10.1097/MPG. 0000000000002234.

\section{Publisher's Note}

Springer Nature remains neutral with regard to jurisdictional claims in published maps and institutional affiliations.
Ready to submit your research? Choose BMC and benefit from:

- fast, convenient online submission

- thorough peer review by experienced researchers in your field

- rapid publication on acceptance

- support for research data, including large and complex data types

- gold Open Access which fosters wider collaboration and increased citations

- maximum visibility for your research: over $100 \mathrm{M}$ website views per year

At $\mathrm{BMC}$, research is always in progress.

Learn more biomedcentral.com/submissions 